\title{
Aerosol residence times and iodine gas/particle conversion over the North Pacific as determined from Chernobyl radioactivity
}

\author{
Mitsuo Uematsu ${ }^{1 *}$, John T. Merrill ${ }^{1}$, Thomas L. Patterson ${ }^{1}$, Robert A. Duce $^{1}$ \\ and JOSEPH M. PROSPERO ${ }^{2}$ \\ Center for Atmospheric Chemistry Studies, Graduate School of Oceanography, \\ University of Rhode Island, Kingston, Rhode Island 02881, USA ${ }^{1}$ and \\ Division of Marine and Atmospheric Chemistry, Rosenstiel School of Marine and Atmospheric Science, \\ University of Miami, Miami, Florida 33149, USA ${ }^{2}$
}

(Received January 28, 1988; Accepted November 2, 1988)

\begin{abstract}
Radioactivity from the Chernobyl accident present on aerosols was measured at several island sites and on a ship in the North Pacific. The radioactivity arrived at the various sites located from $11^{\circ}-64^{\circ} \mathrm{N}$ between 6-14 May 1986. Isentropic trajectory analyses and measurement of the natural radioactive species ${ }^{7} \mathrm{Be}$ and ${ }^{222} \mathrm{Rn}$ indicate that the continental air containing Chernobyl fission products (e.g., ${ }^{131} \mathrm{I}$, ${ }^{137} \mathrm{Cs}$ ) was transported to the central North Pacific through the middle troposphere. We estimate the residence time and gas-to-particle conversion times by combining the radionuclide data with surface concentration estimates in Japan. The atmospheric residence time over the North Pacific for the aerosols containing the fission products was 3-5 days. The calculated mean gas-to-particle conversion time for radioactive ${ }^{131}$ I was $2-3$ weeks, with a minimum of $\sim 12$ days. The results indicate that the radioactive submicrometer aerosol and the iodine gas from the Chernobyl explosion have residence and conversion times similar to those of naturally occurring aerosols and gases in the atmosphere.
\end{abstract}

\section{INTRODUCTION}

An explosion occurred at the Chernobyl nuclear power complex near Kiev, USSR $\left(51^{\circ} \mathrm{N}\right.$, $30^{\circ} \mathrm{E}$ ), on 26 April 1986 (GMT). The resulting plume of radioactivity was measured at many locations over Europe during the next several days (Devell et al., 1986; Fry et al., 1986; Kauppinen et al., 1986; Thomas et al., 1986) and over Japan one week later (Aoyama et al., 1986).

When the Chernobyl accident was reported, we began special air filter sampling for radioactive materials at the island stations in the Sea/Air Exchange Program (SEAREX) Air Sampling Network in the North Pacific (see Fig. 1) and on the R/V Moana Wave which had put to sea on 28 April 1986 from Honolulu for an intensive atmospheric/ocean sampling experiment as part of SEAREX.

We report here about long-range transport of the fission products from Chernobyl to the North Pacific and estimates of aerosol residence times and iodine gas-to-particle conversion rate during the transport using natural and artificial radioactive materials.

\section{EXPERIMENTAL}

The 24 hour aerosol samples for the radionuclides were collected daily at the island sites and on the ship by using high-volume airsampling systems $\left(\sim 1.1 \mathrm{~m}^{3} \mathrm{~min}^{-1}\right.$; Uematsu et 


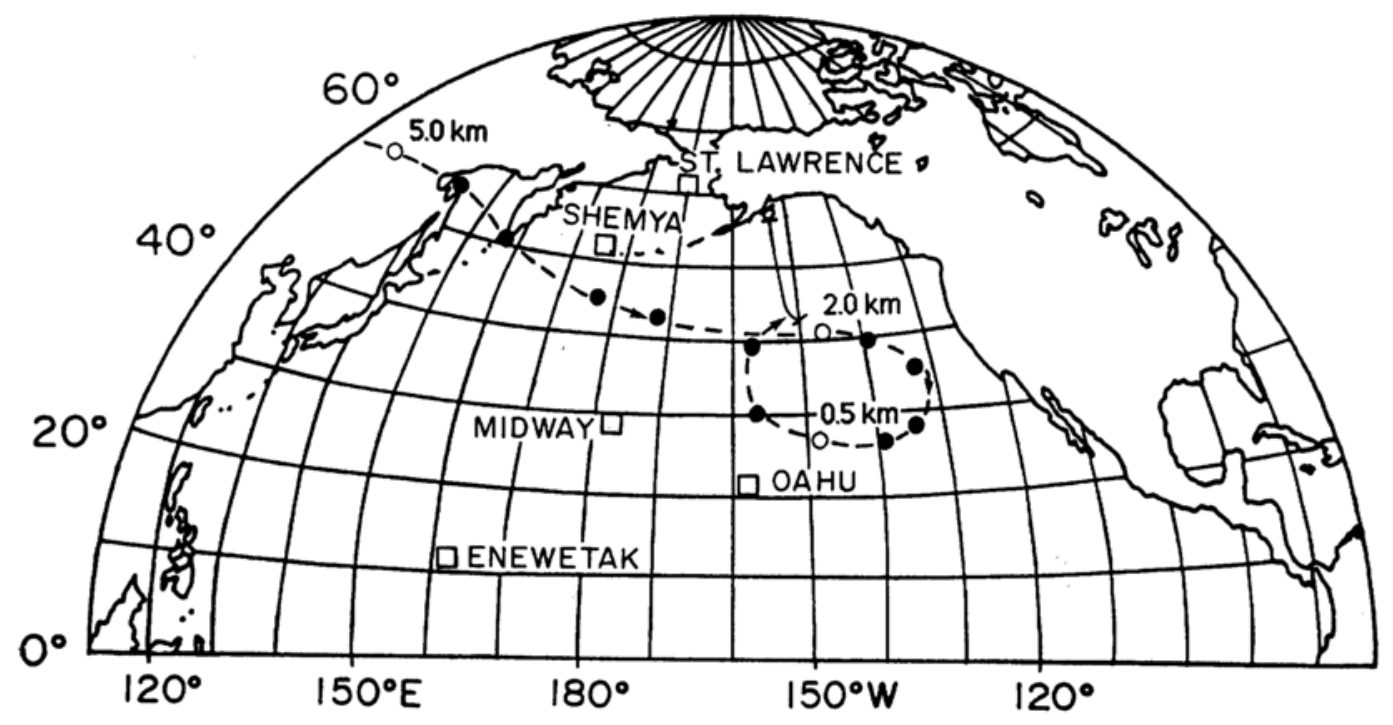

Fig. 1. Sampling stations in the North Pacific and part of the track of R/VMoana Wave. The line (-) is the track between 12 and $18 \mathrm{May}$; data from that period are used for the model calculations (see text). In addition, an isentropic trajectory back in time from the position of R/V Moana Wave early on 12 May, 1986 $\left(\sim 45^{\circ} \mathrm{N}, 152^{\circ} \mathrm{W}\right)$ at $295 \mathrm{~K}$ is given (---). The dots are 1 day apart. The white dots show the locations and the altitude of the air mass on 30 April, 5 and 10 May, respectively. The air mass crossed the central northern North Pacific toward the east at $\sim 4 \mathrm{~km}$ altitude, then descended as it moved to lower latitudes and finally was advected from east to west in the marine boundary layer.

al., 1983). The filters used were Whatman 41 filters $(20 \times 25 \mathrm{~cm})$ at the island sites and Gelman glass fibers filters $(20 \times 25 \mathrm{~cm})$ on the ship. The samples were analyzed for fission products with gamma-ray spectrometry systems at the Rhode Island Nuclear Science Center. There was no apparent difference of the trapping efficiency between the two different kinds of filters examined on the ship, although the mean diameter of particles bearing the fission products were reported to be 0.3-0.9 $\mu \mathrm{m}$ (Bondietti and Brantley, 1986; Kauppinen et al., 1986). Radon-222 was determined by counting the radioactivity of $\mathrm{Rn}$ daughters $\left({ }^{214} \mathrm{~Pb}\right.$ and $\left.{ }^{214} \mathrm{Bi}\right)$ on aerosols using techniques described by Larson and Bressan (1978). Hour long samples for ${ }^{222} \mathrm{Rn}$ were taken twice daily on the ship.

\section{Results AND Discussion}

Transport of fission products to the North Pacific
From the samples collected in early May, apparent peaks of ${ }^{131} \mathrm{I}$ (half-life $8.0 \mathrm{~d}$ ), ${ }^{140} \mathrm{La}$ (halflife $1.7 \mathrm{~d}$ ), ${ }^{103} \mathrm{Ru}$ (half-life $39 \mathrm{~d}$ ), ${ }^{140} \mathrm{Ba}$ (half-life 13d), ${ }^{134} \mathrm{Cs}$ (half-life $2.1 \mathrm{y}$ ) and ${ }^{137} \mathrm{Cs}$ (half-life $30 \mathrm{y}$ ) were identified by the gamma ray spectra, while there was little or no peak due to the radioactivities of these fission products in earlier samples.

Daily atmospheric concentrations of ${ }^{131} \mathbf{I}$ (half-life $8.0 \mathrm{~d}$ ) observed at the stations are shown in Fig. 2. Radioactive materials from Chernobyl were detected at Midway $\left(28^{\circ} \mathrm{N}\right.$, $177^{\circ} \mathrm{W}$ ) between 6 and 7 May; at St. Lawrence $\left(64^{\circ} \mathrm{N}, 172^{\circ} \mathrm{W}\right)$ between 6 and $8 \mathrm{May}$; and at Shemya $\left(53^{\circ} \mathrm{N}, 174^{\circ} \mathrm{E}\right)$ between 6 and 8 May. The radioactivity arrived at all three sites at approximately the same time. The leading edge of the air mass containing radioactive materials arrived at Oahu $\left(21^{\circ} \mathrm{N}, 158^{\circ} \mathrm{W}\right)$ on 10 May but did not reach the Moana Wave (which was then located at $45^{\circ} \mathrm{N}, 152^{\circ} \mathrm{W}$ ) until 12 May. Weekly samples collected at Enewetak $\left(11^{\circ} \mathrm{N}, 162^{\circ} \mathrm{E}\right)$ in- 


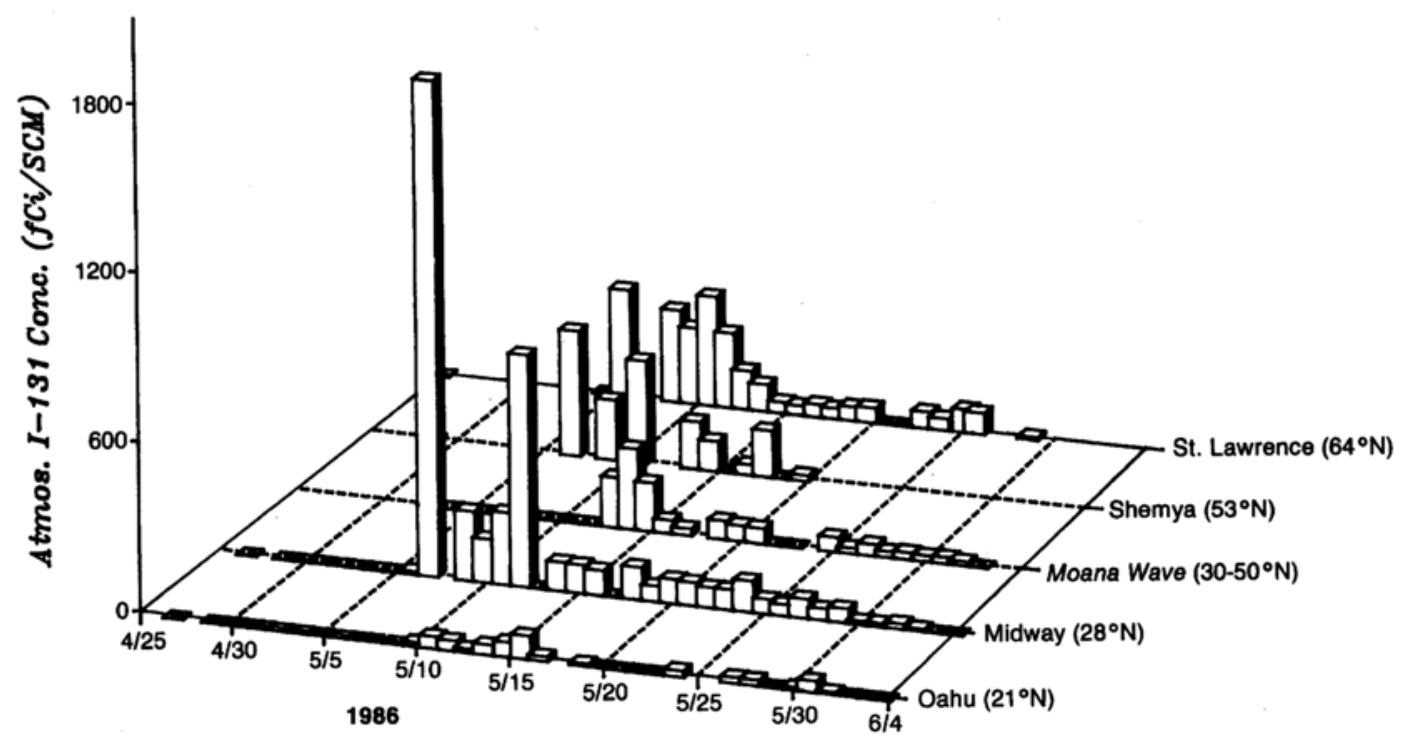

Fig. 2. Daily atmospheric concentrations of ${ }^{131} I$ (fCi/SCM: fCi per standard cubic meter) observed at the stations in the North Pacific during the period from April 25 to June 4. After Uematsu and Duce (1986).

dicate that the fission products reached there sometime between 7 and 14 May.

The highest concentration of ${ }^{131} \mathrm{I}$ was observed at Midway, where $\sim 1800 \mathrm{fCim}^{-3}$ were measured during the 7-9 May period (see Fig. 2). While the concentrations measured north of Midway were lower, the decrease was not as dramatic as it was to the south: the highest concentrations of ${ }^{131} \mathrm{I}$ measured at Oahu never exceeded $53 \mathrm{fCi} \mathrm{m}^{-3}$, while concentrations north of Midway reached several hundred $\mathrm{fCi} \mathrm{m}^{-3}$ at all stations. The concentrations of fission products at the North Pacific sites had decreased to near the detection limits by mid-June. No Chernobyl radioactivity was observed in any samples collected at South Pacific stations (e.g., Nauru, American Samoa, Norfolk) by the end of 1986.

\section{Air trajectory and meteorological analyses}

In Fig. 1, we show a sketch of the isentropic trajectories (Merrill et al., 1985) at the $295 \mathrm{~K}$ (the layer which enters the surface boundary layer near $30^{\circ} \mathrm{N}$ ) for air reaching the ship's location early on 12 May and for air reaching Japan on 2 May. On other days during this period the trajectories for air reaching Japan, Oahu and the vessel follow a similar pattern indicating a common origin for the air containing the radioactive debries. These trajectories indicate clearly that the slow flow of air around the semipermanent anticyclone northeast of Hawaii accounts for the relatively late appearance of the fission products east of $160^{\circ} \mathrm{W}$. The trajectory-based transit times from the Asian coast to Oahu and the ship sites are $\sim 8$ and $\sim 10$ days, respectively. The transport speed during the period 6-10 May $\left(\sim 8 \mathrm{~m} \mathrm{~s}^{-1}\right)$ is much slower than that during the period 1-3 May $\left(\sim 20 \mathrm{~m} \mathrm{~s}^{-1}\right)$. Furthermore, the rapid movement on 3-5 May of air near $45^{\circ} \mathrm{N}$, $180^{\circ}$ towards the southeast is associated with the intrusion into the high of a cold front associated with a strong low centered in the Bering Sea.

Relationship between artificial and natural radionuclides on the ship

In Fig. 3, the concentrations of ${ }^{222} \mathrm{Rn},{ }^{7} \mathrm{Be}$, ${ }^{131} \mathrm{I}$ and ${ }^{137} \mathrm{Cs}$ during the SEAREX cruise are plotted versus time. Each of these radionuclides has a different source: ${ }^{222} \mathrm{Rn}$ (half-life $3.8 \mathrm{~d}$ ) is emitted from continental soil; ${ }^{7} \mathrm{Be}$ (half-life $53 \mathrm{~d}$ ) is produced by cosmic rays in the upper troposphere and lower stratosphere; ${ }^{131} \mathrm{I}$ and ${ }^{137} \mathrm{Cs}$ were 


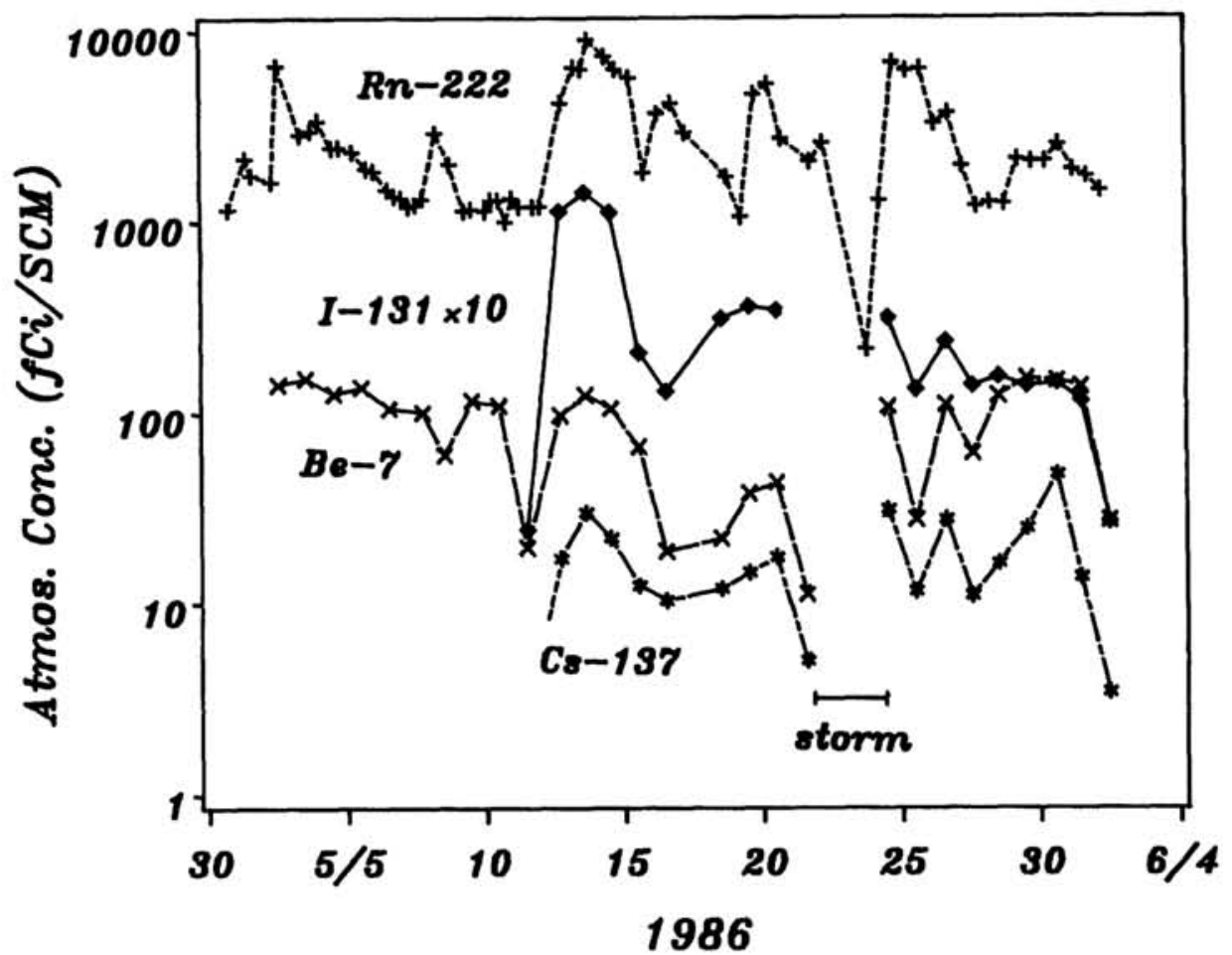

Fig. 3. The atmospheric concentrations of ${ }^{222} \mathrm{Rn},{ }^{7} \mathrm{Be},{ }^{131} \mathrm{I}$ and ${ }^{137} \mathrm{Cs}$ observed on the Moana Wave in 1986, decay corrected to the midpoint of the sampling period.

primarily attributable to the Chernobyl accident. The variations of the concentrations with time, however, were similar to each other, especially during the early period of the sampling. As an example, the peak concentrations for each of these substances occur on 13-16 May.

The transport pattern indicated in Fig. 1 would account for the coincident peaks, as ${ }^{7} \mathrm{Be}$ would be added to the air mass carrying the fission products in the upper troposphere and ${ }^{222} \mathrm{Rn}$ would be injected into the air mass in the middle troposphere along the path over Asia. This pattern is similar to the transport path of mineral aerosol to the central Pacific (Uematsu et al., 1983).

Transit time of fission products from over Japan to the ship

The time series of radioactive materials observed at Tsukuba, Japan (Aoyama et al., 1986) showed that the first major pulse of Chernobyl radioactivity occurred there during the period 38 May. This peak evidently corresponds to the event observed on the ship during the period 1318 May. If so, the transit time from near the coast of the Asian continent to the ship site was $\sim 10$ days, in good agreement with the transit time estimated from the trajectory analysis. Additional trajectory analyses (not shown) indicate that the radioactive materials moved eastward from $90^{\circ} \mathrm{E}$ to $120^{\circ} \mathrm{E}$ at $\sim 55^{\circ} \mathrm{N}$ and that the flow split so that some of this material reached Japan on 3-8 May, while some continued to the east. Some of this material subsided to the surface east of $160^{\circ} \mathrm{W}$ where the ship was located. Subsiding anticyclonic flow which would bring upper tropospheric material to the North Pacific marine boundary layer has been documented previously (Merrill et al., 1985; Uematsu et al., 1983). 
Estimates of air mass mixing, removal of particle and gas-to-particle conversion

Based on the transit time and the concentration of radionuclides measured over Japan and on the ship (see Table 1), we can calculate the first order rate constants for mixing (or dilution) of the air mass as it moves across the Pacific, for removal of the aerosol, and for gas to particle conversion for iodine. The decreasing concentration of substance $x$ with time can be expressed as a first order relationship

$$
N=N_{0} \exp \left(-\lambda_{x} t\right)
$$

where $N$ is the concentration measured on the ship, $N_{0}$ is the concentration measured in Japan or estimated concentration over the continent, $\lambda_{x}$ is an apparent first order process rate constant for $x$, and $t$ is the transit time between the ship site and Japan or the continent.

For ${ }^{222} \mathrm{Rn}$, the concentration decreases only by radioactive decay and by mixing or dilution of the air mass with time. Therefore $\lambda_{R n}$, the total apparent rate constant for concentration decrease, can be expressed as

$$
\lambda_{R n}=\lambda_{m}+\lambda_{d 1}
$$

where $\lambda_{m}$ is the mixing constant for the air mass and $\lambda_{d 1}$ is the radioactive decay constant for ${ }^{222} \mathrm{Rn}, 0.18 \mathrm{~d}^{-1}$. Here $\lambda_{R n}, 0.30 \mathrm{~d}^{-1}$, is obtained from (1) by assuming that the ${ }^{222} \mathrm{Rn}$ concentration at ground level over Japan, which is the eastern end of the source regions that supplies ${ }^{222} \mathrm{Rn}$ to the North Pacific. By this assumption, $\lambda_{m}$ obtained is the maximal value. However, no data for ${ }^{222} \mathrm{Rn}$ in Japan are available during this period in 1986. A value of $125 \mathrm{pCi} \mathrm{m}^{-3}$ (90-200 $\mathrm{pCi} \mathrm{m}^{-3}$ ) as measured at Nagoya, Japan (Shimo et al., 1983) in 1981 was used. If ${ }^{222} \mathrm{Rn}$ in the air mass containing the fission products was injected only from the Chernobyl region and not from any other places through the transport, $\lambda_{R n}$ is $0.19 \mathrm{~d}^{-1}$ which is minimal value. According to Lambert et al. (1982), a typical concentration of ${ }^{222} \mathrm{Rn}$ is $\sim 125 \mathrm{pCi} \mathrm{m}^{-3}$ at ground level over continents. From (2), $\lambda_{m}$ is then $\leq 0.01-0.12 \mathrm{~d}^{-1}$ and a mean mixing time of $\sim 8-\geq 100$ days is obtained. This same mean mixing time is assumed
Table 1. The mean and standard deviation of concentrations of radioactivity observed during the first Chernobyl plume at Japan and over the eastern North Pacific

\begin{tabular}{lcccccc}
\hline \multirow{2}{*}{ Nuolide } & \multicolumn{2}{c}{$\begin{array}{c}\text {Japan}^{*} \\
\left(\mathrm{fCi} \mathrm{m}^{-3}\right)\end{array}$} & & \multicolumn{2}{c}{$\begin{array}{c}\text { Ship** } \\
\left(\mathrm{fCi} \mathrm{m}^{-3}\right)\end{array}$} \\
\cline { 2 - 3 } \cline { 6 - 7 } & Mean & s.d. & & Mean & s.d. \\
\hline${ }^{222} \mathrm{Rn}$ & $125000^{\dagger}$ & - & & 6400 & 2300 \\
${ }^{137} \mathrm{Cs}$ & 890 & 400 & & 31 & 15 \\
${ }^{131} \mathrm{I}$ & 4100 & 1500 & & 120 & 80 \\
${ }^{131} \mathrm{I} /{ }^{137} \mathrm{Cs}^{\dagger+}$ & 4.9 & 1.4 & & 3.3 & 1.2 \\
\hline
\end{tabular}

*Tsukuba, May 3-8, 1986 (Aoyama et al., 1986).

** $45^{\circ}-57^{\circ} \mathrm{N}, 153^{\circ}-160^{\circ} \mathrm{W}$, May $13-18,1986$.

${ }^{\dagger}$ Shimo et al. (1983).

${ }^{+}$The mean of. the ratios for each sample.

to apply to all radionuclides in subsequent calculations.

The concentration of ${ }^{137} \mathrm{Cs}$ decreases by mixing and by removal of particles from the air during transport. Radioactive decay for ${ }^{137} \mathrm{Cs}$ can be neglected in this case. Thus

$$
\lambda_{C s}=\lambda_{r}+\lambda_{m}
$$

where $\lambda_{r}$ is the aerosol removal rate constant. $\lambda_{c s}$ is $0.34 \mathrm{~d}^{-1}$, obtained from (1). From (3) $\lambda_{r}$ is then $0.22-0.33 \mathrm{~d}^{-1}$, and the aerosol residence time is $3.0-4.5$ days.

The concentration of particulate ${ }^{131} \mathrm{I}$ decreases as a result of radioactive decay, air mass mixing and removal of particles. In addition, particulate ${ }^{131} \mathrm{I}$ is formed by gas to particle exchange processes from gaseous ${ }^{131} \mathrm{I}$. More than 60 percent of the total ${ }^{131} \mathrm{I}$ from the Chernobyl release was present in the gas phase (Aoyama et al., 1986; Bondietti and Brantley, 1986). If we assume that ${ }^{131} \mathrm{I}$ in the air is removed only in particulate form and that the removal and mixing rates of particulate ${ }^{131} \mathrm{I}$ are similar to ${ }^{137} \mathrm{Cs}$, then

$$
\lambda_{I}=\lambda_{d 2}+\lambda_{m}+\lambda_{r}-\lambda_{g}
$$

where $\lambda_{d 2}$ is the radioactive decay constant for ${ }^{131} \mathrm{I}, 0.086 \mathrm{~d}^{-1}$ and $\lambda_{g}$ is the rate constant for converting gaseous to particulate iodine (i.e., the conversion is a source for atmospheric particulate $\left.{ }^{131} \mathrm{I}\right) . \lambda_{I}$ is $0.35 \mathrm{~d}^{-1}$ from (1). $\lambda_{g}$ is then $0.08 \mathrm{~d}^{-1}$, equivalent to a mean gas-to-particle 
conversion time of $\sim 13$ days.

Equations (1), (3), and (4) can also be combined to yield an alternate estimate of $\lambda_{g}, \lambda_{g *}$, by using the ratios of particulate ${ }^{131} \mathrm{I}$ to ${ }^{137} \mathrm{Cs}$ at the two sites to obtain the ${ }^{131} \mathrm{I}$ gas-to-particle conversion rate.

$$
\lambda_{g *}=\left(\ln \left(R / R_{0}\right) / t\right)+\lambda_{d 2}
$$

where $R$ and $R_{0}$ are the ratios of particulate ${ }^{131} \mathrm{I}$ to ${ }^{137} \mathrm{Cs}$ on the ship and in Japan, respectively. If the decrease of the $R / R_{0}$ ratio followed the radioactive decay of ${ }^{131} \mathrm{I}$ with time, this would indicate no gas-to-particle conversion. If the decrease of the ratio is smaller than that attributable to the radioactive decay of ${ }^{131} \mathrm{I}$, then we can ascribe the difference to the gas-to-particle conversion of iodine. $\lambda_{g *}$ is calculated to be $0.05 \mathrm{~d}^{-1}$. The relationship between $R / R_{0}$ and the mean gas-to-particle conversion time $\left(1 / \lambda_{g_{*}}\right)$ is plotted in Fig. 4. The mean gas-to-particle conversion time is $\sim 20$ days (see Fig. 4). In contrast to the other calculations the uncertainty in the transit time, $t$, does not significantly affect the value of $1 / \lambda_{g *}$. However, the variation of $R / R_{0}$ (coefficient of variation is 46 percent) results in a large uncertainty in $1 / \lambda_{g *}$. It appears from Fig. 4 that the gas-to-particle conversion time for ${ }^{131} \mathrm{I}$ is a minimum of 12 days.

Comparison of the constants with that of naturally occurring aerosols and gases

The results of the various calculations are summarized as follows. A relatively long mean mixing time $\left(1 / \lambda_{m}\right)$ of $>8$ days was estimated from ${ }^{222} \mathrm{Rn}$ data. The residence time $\left(1 / \lambda_{r}\right)$ for aerosol particles in the marine atmosphere containing the radioactive material during this event was 3-5 days, a value that agrees well with the mean tropospheric residence time of continental submicrometer aerosol reported by Graustein and Turekian (1986) using ${ }^{210} \mathrm{~Pb}$ and ${ }^{137} \mathrm{Cs}$ measurements. The mean gas-to-particle conversion time $\left(1 / \lambda_{g}\right.$ or $\left.1 / \lambda_{g *}\right)$ for iodine over the Pacific was calculated to be 2-3 weeks, with a minimum of 12 days. This estimate also agrees with the previously reported residence time of 17-19 days for total gaseous iodine (Rahn et al., 1976). By

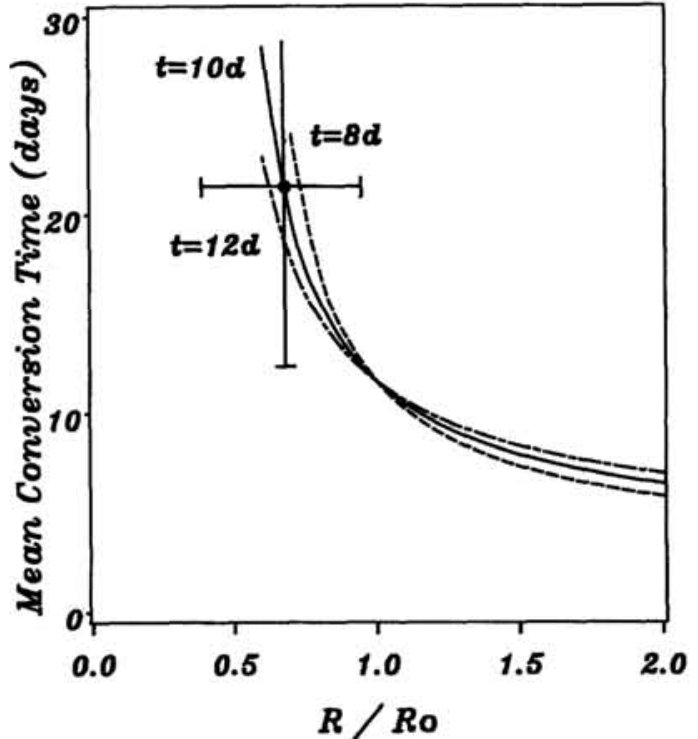

Fig. 4. The relationship between $R / R_{0}$ and the mean gas-to-particle conversion time. $t$ is the transit time from Japan to the ship location. The symbol (๑) shows the mean $R / R_{0}$ of $0.67 \pm 0.31$, and the bar represents \pm 1 standard deviation from the mean.

propagating the uncertainties in the mean values of the radionuclide concentrations and the $\mathrm{Rn}$ concentration in Japan, as well as the range of estimated travel times we estimate that the uncertainty of the mixing, residence, and conversion times is approximately a factor of two. Despite these uncertainties, this approach provides a means of obtaining an independent estimate of mixing rates, aerosol residence times, and gas/particle conversion rates for iodine. This study shows that the radioactive submicrometer aerosol and the iodine gas from the Chernobyl explosion have residence and conversion times similar to those of naturally occurring aerosols and gases in the atmosphere.

\section{Conclusion}

Our measurement of atmospheric radionuclides from the Chernobyl accident collected at several island sites and on a ship in the North Pacific lead to the following conclusions:

1. The radioactivity arrived at the various 
sites located from $11^{\circ}-64^{\circ} \mathrm{N}$ over the North Pacific between 6-14 May 1986. The transit times were about 10-14 days (more than 7000 $\mathrm{km}$ from Chernobyl to these sites).

2. Isentropic trajectory analyses and measurement of the natural radionuclides indicate that the continental air containing Chernobyl fission products was transported to the central North Pacific through the middle troposphere.

3. The mean mixing time for boundary layer air parcels with the free troposphere is $>8$ days. The atmospheric residence time over the North Pacific for the aerosols containing the fission products was 3-5 days. The calculated mean gas-to-particle conversion time for radioactive ${ }^{131}$ I was $2-3$ weeks, with a minimum of $\sim 12$ days.

4. The radioactive submicrometer aerosol and the iodine gas from the Chernobyl explosion have residence and conversion times similar to those of naturally occurring aerosols and gases in the atmosphere.

Acknowledgments-We wish to thank the staff of the Rhode Island Nuclear Science Center for providing counting facilities. This research was supported by NSF grants OCE 84-05605, OCE 84-05608, ATM 8311694 and ATM 83-11335 as a part of the SEAREX Program and the North Pacific Tropospheric Transport and Deposition Study.

\section{REFERENCES}

Aoyama, M., Hirose, K., Suzuki, Y., Inoue, H. and Sugimura, Y. (1986) High level radioactive nuclides in Japan in May. Nature 321, 819-820.

Bondietti, E. A. and Brantley, J. N. (1986) Characteristics of Chernobyl radioactivity in Tennessee. Nature 322, 313-314.
Devell, L., Tovedal, H., Bergström, U., Appe1gren, A., Chyssler, J. and Andersson, L. (1986) Initial observations of fallout from the reactor accident at Chernobyl. Nature 321, 192-193.

Fry, F. A., Clarke, R. H. and O'Riordan, M. C. (1986) Early estimates of UK radiation doses from the Chernobyl reactor. Nature 321, 193-195.

Graustein, W. C. and Turekian, K. K. (1986) ${ }^{210} \mathrm{~Pb}$ and ${ }^{137} \mathrm{Cs}$ in air and soils measure the rate and vertical profile of aerosol scavenging. J. Geophys. Res. 91, 14355-14366.

Kauppinen, E. I., Hillamo, R. E., Aaltonen, S. H. and Sinkko, K. T. S. (1986) Radioactivity size distributions of ambient aerosols in Helsinki, Finland, during May 1986 after the Chernobyl Accident: Preliminary report. Environ. Sci. Technol. 20, 1257-1259.

Lambert, G., Polian, G., Sanak, J., Arodouin, B., Buisson, A., Jegou, A. and LeRoulley, J. C. (1982) Radon and daughter products cycle: application to troposphere-stratosphere exchanges. Ann. Geophys. 38, 497-531, (French).

Larson, R. E. and Bressan, D. J. (1978) Automatic radon counter for continual unattended operation. Rev. Sci. Instrum., 49, 965-969.

Merrill, J. T., Bleck, R. and Avila, L. (1985) Modeling atmospheric transport to the Marshall islands. J. Geophys. Res. 90, 12927-12936.

Rahn, K. A., Borys, R. D. and Duce, R. A. (1976) Tropospheric halogen gases: Inorganic and organic components. Science 192, 549-550.

Shimo, M., Ogawa, H., Takiguchi, Y., Ojima, S. and Ikebe, Y. (1983) Evaluation of dilution time. Res. Rep. Environ. Sci., B158-R11-1, 79-81, (Japanese).

Thomas, A. J. and Martin, J. M. (1986) First assessment of Chernobyl radioactive plume over Paris. Nature 321, 817-819.

Uematsu, M. and Duce, R. A. (1986) Tracking the Chernobyl plume across the Pacific. Maritimes 30, 1-4.

Uematsu, M., Duce, R. A., Prospero, J. M., Chen, L. Q., Merrill, J. T. and McDonald, R. L. (1983) Transport of mineral aerosol from Asia over the North Pacific Ocean. J. Geophys. Res. 88, 53435352. 